\title{
Comparison of salivary total antioxidant levels in male smokers and non-smokers according to their personality types
}

\section{Porównanie całkowitej zdolności antyoksydacyjnej śliny u palących i niepalących mężczyzn w odniesieniu do ich typów osobowości}

\author{
Hamed Mortazavi ${ }^{1, A, E, F}$, Azadeh Ghasemi ${ }^{2, B, C}$, Mohammad Reza Vatankhah ${ }^{3, C, D}$ \\ ${ }^{1}$ Department of Oral Medicine, School of Dentistry, Shahid Beheshti University of Medical Sciences, Tehran, Iran \\ ${ }^{2}$ Dental private office, Tehran, Iran \\ ${ }^{3}$ Students' Research Committee, School of Dentistry, Shahid Beheshti University of Medical Sciences, Tehran, Iran \\ A - research concept and design; $B$ - collection and/or assembly of data; $C$ - data analysis and interpretation; \\ $D$ - writing the article; $E$ - critical revision of the article; $F$ - final approval of the article
}

Address for correspondence

Hamed Mortazavi

E-mail: hamedmortazaviz2013@gmail.com

Funding sources

None declared

Conflict of interest

None declared

Received on August 30, 2019

Reviewed on September 27, 2019

Accepted on November 20, 2019

Published online on June 29, 2020

Cite as

Mortazavi H, Ghasemi A, Vatankhah MR. Comparison of salivary

total antioxidant levels in male smokers and non-smokers

according to their personality types. Dent Med Probl.

2020;57(2):145-148. doi:10.17219/dmp/114440

D0I

$10.17219 / \mathrm{dmp} / 114440$

Copyright

( 2020 by Wroclaw Medical University

This is an article distributed under the terms of the

Creative Commons Attribution 3.0 Unported License (CC BY 3.0)

(https://creativecommons.org/licenses/by/3.0/).

\section{Abstract}

Background. Cigarette smoking is a major global health problem, associated with various oral diseases, such as oral cancers. Salivary antioxidants may play an important role in fighting against radicals and the oxidative components of cigarettes, which can cause DNA damage. Furthermore, psychological stress, which occurs more often in individuals with type A personality, affects plasma antioxidant levels.

Objectives. The objective of this study was to compare the levels of salivary total antioxidant capacity (TAC) between smokers and non-smokers according to their personality types.

Material and methods. In this descriptive cross-sectional study, saliva samples were collected from 40 male smokers (with $\geq 0.1$ pack-years) and 40 male non-smokers. After centrifugation, the samples were assessed using an enzyme-linked immunosorbent assay (ELISA) kit. Pearson's correlation, Welch's $t$-test and the one-way analysis of variance (ANOVA) test were used for statistical analyses.

Results. The TAC of saliva in smokers was significantly lower than in non-smokers ( $p=0.019)$. Type A and type B smokers showed no significant decrease in $\operatorname{TAC}(p>0.05$ and $p=0.05$, respectively) as compared to type $A$ and type $B$ non-smokers, respectively. Type $A$ smokers reported a higher number of cigarettes smoked per day as compared to smokers with type B personality $(p=0.043)$.

Conclusions. Smoking cigarettes was associated with a significant decrease in salivary TAC. However, the personality type did not affect salivary TAC in the present study.

Key words: personality, antioxidants, saliva, antioxidant, smoking tobacco

Słowa kluczowe: osobowość, antyoksydanty, ślina, antyoksydacyjny, palenie tytoniu 


\section{Introduction}

Smoking has various negative effects on oral health. Also, it is considered as a major risk factor for oral cancers. ${ }^{1,2}$ Furthermore, smoking tobacco is positively associated with buccal cell mutations, ${ }^{3}$ periodontal diseases ${ }^{4}$ and premalignant lesions. ${ }^{5}$

Reactive oxygen species, reactive nitrogen species as well as radicals are amongst the numerous toxic components found in cigarette smoke. ${ }^{6}$ These oxidants and radicals can lead to oxidative DNA damage, the damage of cellular components, the inhibition of apoptosis, and increased angiogenesis. Hence, they are related to oral cancer initiation, promotion and progression. ${ }^{7,8}$

The disproportion between the levels of oxidative components (e.g., reactive oxygen species and free radicals) and antioxidants may be associated with several oral pathologies. ${ }^{9}$ As a biological fluid, saliva contains antioxidant molecules, such as glutathione and uric acid, and enzymes, such as superoxide dismutase (SOD), guaiacol peroxidase (GP) and glutathione peroxidase (GSH-PX). ${ }^{10}$ Cigarette smoke may interfere with the antioxidants in saliva. A previous study showed that smoking a single cigarette induced a significant reduction in the concentration of glutathione in saliva. ${ }^{11}$ Also, another study demonstrated that salivary TAC levels were significantly lower in smokers as compared to non-smokers. ${ }^{12}$

It has been shown that psychological stress can increase DNA oxidation and lipid peroxidation, and decrease the total antioxidant capacity (TAC) of plasma in university students. ${ }^{13}$ Another study showed increased peroxidation levels and decreased TAC levels of plasma in patients with depression. ${ }^{14}$ Both psychological stress and depression occur with a higher incidence in persons with type $\mathrm{A}$ personality. These individuals are more impatient, more competitive and more aggressive. Also, they tend to exhibit addictive behaviors, such as cigarette smoking. ${ }^{15}$

The current lack of evidence has led us to design this descriptive cross-sectional study to measure and compare the TAC levels of saliva in smokers and non-smokers according to their personality types.

\section{Material and methods}

This descriptive cross-sectional study was conducted between 2016 and 2018. It was approved by the Ethics Committee of Shahid Beheshti University of Medical Sciences in Tehran, Iran (IR.SBMU.RIDS.REC.1395.350).

The sample size required to identify differences between the 2 groups, as stated in a previous similar study, ${ }^{10}$ was 20 subjects in each group, assuming a nondirectional alpha risk of 0.05 and a power of 0.8 . Forty male smokers and 40 male non-smokers were selected using a simple non-randomized sampling method. Each group had equally 20 individuals with type A or type B personality.
The groups consisted of patients attending the Department of Oral Medicine at the School of Dentistry of Shahid Beheshti University of Medical Sciences in Tehran, Iran.

Individuals with a history of $\geq 0.1$ pack-years are considered as smokers. ${ }^{16}$ The inclusion criteria contained the following: the ability to fill out the questionnaire; no consumption of alcohol; age under 60 years; the absence of pregnancy; no presence of oral lesions or systemic diseases, such as diabetes mellitus, leukemia, thalassemia, or rheumatoid arthritis; and not taking medications during the previous 6 months at least.

All individuals signed informed consent. The investigator requested the participants not to eat or drink $2 \mathrm{~h}$ before the collection of saliva. In addition, smokers were prohibited from smoking $1 \mathrm{~h}$ before the collection of saliva. After mouth washing with water and waiting for $2 \mathrm{~min}, 5 \mathrm{~mL}$ of saliva was sampled in an upright resting position between 9 am and $12 \mathrm{am}$. The samples were immediately placed in ice, and then moved to the laboratory. They were centrifuged at $1,000 \mathrm{~g}$ at $4^{\circ} \mathrm{C}$ for $10 \mathrm{~min}$. After removing debris, the samples were preserved at a temperature of $-80^{\circ} \mathrm{C}$. The exact duration of the saliva collection was also recorded to calculate the salivary flow. ${ }^{17}$ A blinded technician measured the TAC levels using an enzyme-linked immunosorbent assay (ELISA) kit (ZellBio GmbH, Rostock, Germany). This kit was able to detect $0.1 \mathrm{mM}$ of TAC, using ascorbic acid as a standard. ${ }^{18,19}$ The DANA-3200 ${ }^{\circledR}$ ELISA reader (Garni Medical Eng. Co., Tehran, Iran) was used to read the results.

To determine the type of personality, we used the selfadministered 14-item Bortner questionnaire in the Persian language with total scores ranging from 0 to 140 , assuming 70 as a borderline. ${ }^{18}$ Results with scores less or more than 70 are considered as type B or type A personality, respectively. The reliability and validity of the Persian version of the Bortner questionnaire were assessed and confirmed in previous separate studies. ${ }^{19,20}$

The analyses were carried out using the IBM SPSS Statistics for Windows software, v. 21 (IBM Corp., Armonk, USA). The comparison of different brands of cigarettes was made using the $X^{2}$ test. Welch's $t$-test was used to compare smoking years, the number of cigarettes smoked per day and age between the groups. To compare the levels of TAC between the groups, the one-way analysis of variance (ANOVA) test was implemented. The statistical significance level of the present study was set at $5 \%$.

\section{Results}

The mean age of the participants was $39.6 \pm 7.32$ years. There was no significant difference in terms of age between the groups $(p>0.05)$.

Table 1 shows that the levels of TAC in smokers were significantly lower than in non-smokers $(p=0.019)$. There 
was no significant difference in the levels of TAC between type A smokers and type A non-smokers $(p>0.05)$, but this difference was at the borderline for the type B group $(p=0.05)$. Furthermore, there was no significant difference in the TAC levels between smokers with regard to their personality types $(p>0.05)$. According to Table 2 , the number of cigarettes smoked per day for the type A group was significantly greater than for the type B group $(p=0.043)$. However, the difference in smoking years between the 2 groups was not significant $(p>0.05)$.

The salivary flow of smokers was lower than that of non-smokers, but the difference was not statistically significant $(p>0.05)$.

Table 1. Comparison of the total antioxidant capacity (TAC) levels between the groups

\begin{tabular}{|l|c|c|c|}
\multicolumn{1}{|c|}{ Group } & $\begin{array}{c}\text { Sample size } \\
(n)\end{array}$ & $\begin{array}{c}\text { TAC } \\
{[\mathrm{U} / \mathrm{L}]}\end{array}$ & p-value \\
\hline Type A smokers & 20 & $0.34 \pm 0.19$ & \multirow{2}{*}{0.840} \\
\hline Type A non-smokers & 20 & $0.39 \pm 0.19$ & \\
\hline Type B smokers & 20 & $0.24 \pm 0.15$ & \multirow{2}{*}{$0.050^{* *}$} \\
\hline Type B non-smokers & 20 & $0.39 \pm 0.17$ & \\
Type A and type B smokers & 40 & $0.29 \pm 0.17$ & \multirow{2}{*}{$0.019^{*}$} \\
Type A and type B non-smokers & 40 & $0.39 \pm 0.18$ & \\
Type A smokers & 20 & $0.34 \pm 0.19$ & 0.323 \\
\hline Type B smokers & 20 & $0.24 \pm 0.15$ & \\
\hline
\end{tabular}

Data presented as mean \pm standard deviation $(M \pm S D)$

* statistically significant; ${ }^{* *}$ at the borderline of statistical significance.

Table 2. Factors associated with cigarette smoking in each smoker group

\begin{tabular}{|l|c|c|c|}
\multicolumn{1}{|c|}{ Factor } & $\begin{array}{c}\text { Type A smokers } \\
(n=20)\end{array}$ & $\begin{array}{c}\text { Type B smokers } \\
(n=20)\end{array}$ & $p$-value \\
\hline $\begin{array}{l}\text { Mean duration of cigarette } \\
\text { smoking [years] }\end{array}$ & 18.35 & 18.00 & 0.897 \\
$\begin{array}{l}\text { Mean number of cigarettes } \\
\text { smoked per day }\end{array}$ & 12.40 & 8.65 & $0.043^{*}$ \\
\hline
\end{tabular}

* statistically significant.

\section{Discussion}

The maximum prevalence of cigarette smoking is seen between the age of 30 and $49 . .^{21,22}$ Similarly to previous studies, ${ }^{2,10}$ the mean age of participants in this study was in the aforesaid range.

It has been shown that the levels of TAC are significantly higher in males. ${ }^{23}$ For this reason and to eliminate the possible effect of sex, we only included male participants in the present study.

The measurement of TAC is better than the measurement of all known antioxidants separately, as it requires less time, and takes into account the activity of unknown antioxidants as well as the positive or negative interactions between different antioxidants. ${ }^{11}$

In the present study, salivary TAC in smokers was significantly lower than in non-smokers. This outcome was similar to those of some previous studies, reporting lower levels of TAC or SOD, GP and GSH-PX separately. ${ }^{2,10}$ Nevertheless, some other studies showed no significant difference in salivary TAC between smokers and nonsmokers. ${ }^{24}$ Conversely, previous research showed significantly higher levels of TAC in smokers as compared to non-smokers. ${ }^{25}$ These controversies may be related to the differences in the study design, inclusion and exclusion criteria, sample size, saliva sampling methods, intensity and duration of the smoking habit, and antioxidant measurement methods.

Although some studies reported a significantly lower salivary flow for smokers, our results showed no significant difference in the salivary flow between the 2 groups, confirming the outcomes of previous research. ${ }^{24}$

Individuals with type A or type $\mathrm{B}$ personality exhibit different psychological states; however, our findings showed no significant difference between the 2 types in the duration of cigarette smoking, although participants with type A personality reported a significantly higher number of cigarettes smoked per day as compared to participants with type B personality. These findings are parallel to prior evidence and can indicate that smoking is more common among people with type A personality than in the case of type B personality. ${ }^{26}$

Individuals with type A personality were smoking more cigarettes per day as compared to type B individuals, but they did not have lower levels of TAC. This result is similar to that of a previous study, which showed no significant difference in nicotine intake between the 2 different personality types. However, that study reported similar smoking behaviors in type A and type B smokers. ${ }^{27}$ Our findings with different smoking behaviors (more cigarettes per day in the type A personality group) are in line with the findings of the aforementioned study with similar smoking behaviors in the 2 groups. Maybe other factors, such as the number of puffs per cigarette or the duration of each puff, influence this controversy.

Another study demonstrated that the administration of nicotine caused a significant change in the plasma lipid profile, promoting lipid peroxidation in plasma. This increase in peroxidation decreases the levels of SOD, catalase and GSH-PX in plasma. ${ }^{28}$

What can be regarded as a limitation of this study is the fact that we did not measure some of the known smoking behavior indicators, such as the number of puffs per cigarette and the duration of each puff.

The personality type affects more than a single smoking behavior that can lead to an alteration in salivary TAC levels; therefore, assessing other factors, such as differences in the diet, working conditions and socioeconomic situation, is recommended for further studies.

This study lays an important foundation for future research; more studies on the possible relation between personality types and the TAC levels are needed with a higher sample size and different methods used. Due to a large number of people involved, even if the effect of personality 
types on the TAC levels is generally small, such studies may provide important information that can be used to modify prevention policies and cessation programs.

The smoker's personality profile is considered as an important obstacle to cessation. ${ }^{29}$ In addition, smoking tobacco is an important risk factor for oral cancers. Therefore, properly planned prevention policies and cessation programs, in order to be efficacious, should take into account the aspect of personality. ${ }^{1}$

\section{Conclusions}

The results of this study suggest that smoking cigarettes is associated with a significant decrease in salivary TAC. However, there was no significant difference in salivary TAC levels between type A and type B smokers.

\section{ORCID iDs}

Hamed Mortazavi (i) https://orcid.org/0000-0002-0778-5299

Azadeh Ghasemi (1) https://orcid.org/0000-0002-9550-5436

Mohammad Reza Vatankhah (1) https://orcid.org/0000-0001-9988-6005

\section{References}

1. Warnakulasuriya S. Causes of oral cancer - an appraisal of controversies. Br Dent J. 2009;207(10):471-475.

2. Abdolsamadi HR, Goodarzi MT, Mortazavi H, Robati M, AhmadiMotemaye F. Comparison of salivary antioxidants in healthy smoking and non-smoking men. Chang Gung Med J. 2011;34(6):607-611.

3. Proia NK, Paszkiewicz GM, Sullivan Nasca MA, Franke GE, Pauly JL. Smoking and smokeless tobacco-associated human buccal cell mutations and their association with oral cancer - a review. Cancer Epidemiol Biomarkers Prev. 2006;15(6):1061-1077.

4. Johnson GK, Guthmiller JM. The impact of cigarette smoking on periodontal disease and treatment. Periodontol 2000. 2007;44:178-194.

5. Jahanbani J. Prevalence of oral leukoplakia and lichen planus in 1,167 Iranian textile workers. Oral Dis. 2003;9(6):302-304.

6. Pryor WA, Stone K. Oxidants in cigarette smoke. Radicals, hydrogen peroxide, peroxynitrate, and peroxynitrite. Ann N Y Acad Sci. 1993;686:12-27.

7. Pfeifer GP, Denissenko MF, Olivier M, Tretyakova N, Hecht SS, Hainaut P. Tobacco smoke carcinogens, DNA damage and p53 mutations in smoking-associated cancers. Oncogene. 2002;21(48):7435-7451.

8. Choudhari SK, Chaudhary M, Gadbail AR, Sharma A, Tekade S. Oxidative and antioxidative mechanisms in oral cancer and precancer: A review. Oral Oncol. 2014;50(1):10-18.

9. Battino M, Ferreiro MS, Gallardo I, Newman HN, Bullon P. The antioxidant capacity of saliva. J Clin Periodontol. 2002;29(3):189-194.

10. Bakhtiari S, Azimi S, Mehdipour M, Amini S, Elmi Z, Namazi Z. Effect of cigarette smoke on salivary total antioxidant capacity. J Dent Res Dent Clin Dent Prospects. 2015;9(4):281-284.

11. Bakhtiari S, Taheri JB, Bakhshi M, et al. Effect of vitamin C on salivary total antioxidant capacity in smokers. Iran J Pharm Res. 2012;11(4):1045-1049.

12. Zappacosta B, Persichilli S, De Sole P, Mordente A, Giardina B. Effect of smoking one cigarette on antioxidant metabolites in the saliva of healthy smokers. Arch Oral Biol. 1999;44(6):485-488.

13. Kusano C, Ferrari CKB. Total antioxidant capacity: A biomarker in biomedical and nutritional studies. J Cell Mol Biol. 2008;7(1):1-15.

14. Yanik M, Erel O, Kati M. The relationship between potency of oxidative stress and severity of depression. Acta Neuropsychiatr. 2004;16(4):200-203.

15. Moriana JA, Herruzo J. Type A behavior pattern as a predictor of psychiatric sick-leaves of Spanish teachers. Psychol Rep. 2005;96(1):77-82.
16. Lee $\mathrm{YH}$, Shin $\mathrm{MH}$, Kweon SS, et al. Cumulative smoking exposure, duration of smoking cessation, and peripheral arterial disease in middle-aged and older Korean men. BMC Public Health. 2011;11:94.

17. Navazesh M, Kumar SKS. Measuring salivary flow: Challenges and opportunities. J Am Dent Assoc. 2008;139(Suppl):35S-40S.

18. Walsh JJ, Wilding JM, Eysenck MW. Stress responsivity: The role of individual differences. Pers Individ Differ. 1994;16(3):385-394.

19. Farnodi $F$, Amiri $H$, Jalali $R$. The association of personality type $A$ and $B$ to type 2 diabetes mellitus in patients referring to diabetes center, Kermanshah, 2014. J Clin Res Paramed Sci. 2015;4(3):188-194.

20. Roushan $C R$, Modaresi F. Personality types and mental health impact of systemic lupus erythematosus and rheumatoid arthritis. Hakim Res J. 2003;5(4):255-261.

21. Jha P, Ranson MK, Nguyen SN, Yach D. Estimates of global and regional smoking prevalence in 1995, by age and sex. Am J Public Health. 2002;92(6):1002-1006.

22. Ebadi $M$, Vahdaninia $M$, Azin $A$, et al. Prevalence of tobacco consumption: Iranian health perception survey. Payesh. 2011;10(3):365-372.

23. Lettrichová I, Tóthová L, Hodosy J, Behuliak M, Celec P. Variability of salivary markers of oxidative stress and antioxidant status in young healthy individuals. Redox Rep. 2016;21(1):24-30.

24. Charalabopoulos K, Assimakopoulos D, Karkabounas S, Danielidis V, Kiortsis D, Evangelou A. Effects of cigarette smoking on the antioxidant defence in young healthy male volunteers. Int $J$ Clin Pract. 2005;59(1):25-30.

25. Nagler RM. Altered salivary profile in heavy smokers and its possible connection to oral cancer. Int J Biol Marker. 2007;22(4):274-280.

26. Oyefeso AO, Odeyale MA. Smoking and type A behaviour. Scand J Psychol. 1991;32(1):79-81.

27. Hughes JR, Pickens RW, Gust SW, Hatsukami DK, Svikis DS. Smoking behavior of type A and type B smokers. Addict Behav. 1986;11(2):115-118.

28. Chattopadhyay K, Chattopadhyay BD. Effect of nicotine on lipid profile, peroxidation \& antioxidant enzymes in female rats with restricted dietary protein. Indian J Med Res. 2008;127(6):571-576.

29. de Cássia Rondina R, Gorayeb R, Botelho C. Psychological characteristics associated with tobacco smoking behavior. J Bras Pneumol. 2007;33(5):592-601. 